\title{
Ekstranodal Baş Boyun Diffüz Büyük B Hücreli Lenfomalarının Geriye Yönelik Olarak Değerlendirilmesi ve Nodal Hastalık ile Karşılaştırılması
}

\author{
Retrospective Analysis of Extranodal Involvement \\ of Head and Neck Diffuse Large B Cell \\ Lymphomas and Comparison of Nodal Disease
}

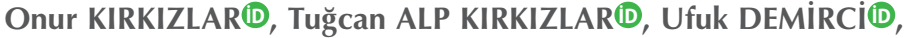

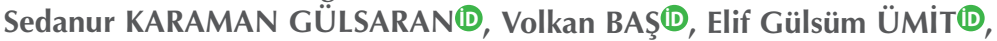 \\ Ahmet Muzaffer DEMIR(D \\ Trakya Üniversitesi Tıp Fakültesi, Hematoloji Bilim Dalı, Edirne, Türkiye
}

\section{öz}

Amaç: Baş boyun bölgesinden nodal veya ekstranodal tutulumlu diffüz büyük B hücreli lenfoma (DBBHL) tanısı alan hastaların klinikopatolojik özellikleri ve toplam sağkalım oranlarını incelemeyi ve karşılaştırmayı amaçladık.

Hastalar ve Yöntem: Çalışmaya primer baş boyun bölgesi ekstranodal veya nodal tutulum ile başvuran DBBHL tanılı 52 erişkin hasta alındı. Hastaların demografik, klinik, patoloji, görüntüleme, tedavi, tedavi cevabı ve prognostik indeksleri değerlendirildi. İzlem ve sağkalım sonuçları gözden geçirildi.

Bulgular: Hastaların 24'ü ekstranodal, 28'i ise nodal gruba dahil edildi. Nodal ve ekstranodal gruplar karşılaştırıldığında cinsiyet, yaş, Ki67 proliferasyon indeksi, BCL-2 pozitifliği, B semptom varlığı, performans durumu, LDH, prognostik indeksler, 1. basamak tedaviye yanıt açısından fark yoktu. Ekstranodal grupta germinal merkez benzeri B hücre kökeni, BCL-6 pozitifliği, erken evre hastalık nodal gruba göre daha yüksek oranda bulundu ve bu yükseklik istatistiksel olarak anlamlı saptandı ( $p$ değerleri sırasıyla 0.010, 0.016, 0.001). Ekstranodal tutulumların dağılımı tonsil (n: 10), tiroid (n: 5), nazofarenks (n: 2), maksiller sinüs (n: 2), parotis bezi (n: 2), nazal (n: 1), dil (n:1) ve bukkal mukoza (n: 1) şeklindeydi. Ortanca sağkalım nodal grupta 37 ay, ekstranodal grupta 43 ay idi. Bu farklılık istatistiksel olarak anlamlıydı $(p=0.022)$.

Sonuç: Ekstranodal tutulum yeri ve sayısı DBBHL'de prognozu belirlemektedir. Çalışmamızda, baş boyun bölgesi primer ekstranodal DBBHL'lerin kökeninin germinal merkez B benzeri hücre yönünde olmasının, semptomların ve görünürlüğünün nodal olanlara göre daha erken olmasının ve dolayısıyla erken tanı ve tedavi şansının olmasının daha iyi sağkalıma neden olduğu sonucuna vardık. Bu nedenle santral sinir sistemi hariç baş boyun bölgesine sınırlı ekstranodal tutulumlar daha iyi bir prognostik belirteç olarak kabul edilebilir.

Anahtar Kelimeler: Diffüz büyük B hücreli lenfoma; Baş; Boyun; Prognoz

\section{ABSTRACT}

Objective: We aimed to analyze and to compare the patients diagnosed with diffuse large B cell lymphoma (DLBCL) from nodal or extranodal head and neck involvement as clinicopathologic features and overall survival rates.

Patients and Methods: We included 52 adult patients who presented with primarly nodal or extranodal head and neck region DLBCL in the study. Patients' demographic, clinical, pathology and imaging data, treatment, response to treatment and prognostic indexes were evaluated. Follow up and survival status were reviewed.

Makale atıfı: Kırkızlar O, Alp Kırkızlar T, Demirci U, Karaman Gülsaran S, Baş V, Ümit EG ve ark. Ekstranodal baş boyun diffüz büyük B hücreli lenfomalarının geriye yönelik olarak değerlendirilmesi ve nodal hastalık ile karşılaştırılması. LLM Dergi 2021;5(2):21-6.

\section{Yazıșma Adresi}

\section{Onur KIRKIZLAR}

Trakya Üniversitesi Tıp Fakültesi, Hematoloji Bilim Dalı Edirne-Türkiye

Geliş: 26.08.2021 - Kabul: 13.10.2021

E-posta: onurkirkizlar@gmail.com 
Results: 24 patients were included into extranodal group while 28 patients in nodal group. Regarding gender, age, Ki67 profliferation index, $\mathrm{BCL}-2$ positivity, presence $\mathrm{B}$ symptoms, performance status, $\mathrm{LDH}$, prognostic indexes, response to 1st line treatment there were not a difference when compared nodal and extranodal groups. Germinal center B cell like origin, BCL- 6 positivity and early stage of the disease were higher in extranodal group and these differences were statistically significant ( $p$ values are $0.010,0.016,0.001$, respectively). The distribution of extranodal involvements were as tonsillery ( $n: 10)$, thyroid ( $n: 5)$, nasopharynx ( $n: 2)$, maxillary sinus ( $n: 2$ ), parotid gland $(n: 2)$, nasal (n: 1), tongue ( $n: 1)$ and buccal mucosa ( $n: 1)$. The median survival time was 37 months in nodal group and was 43 months in extranodal group. This difference was statistically significant ( $p$ value 0.022 ).

Conclusion: The site and the number of the extranodal involvement of DLBCL determines the prognosis of the disease. In our study, we conclude that being the cell of the origin toward to germinal center B like, the chance of earlier detection and treatment of extranodal involvement of this region due to symptoms and being visual earlier than nodal involvement render better survival in the head and neck extranodal DLBCL. Hence extranodal involvements which are limited to head and neck except central nervous system can be approved of a better prognostic factor.

Key Words: Diffuse large b cell lymphoma; Head; Neck; Prognosis

\section{GiRiş}

Diffüz büyük B hücreli lenfoma (DBBHL) non-Hodgkin lenfomaların (NHL) en sık görülen alt tipidir (1). Lenfomalar sıklıkla lenf nodundan kaynaklanmaktadır. Fakat \%30 oranında lenf nodu dışı kaynaklı gelişebilir ve bu durum 'primer ekstranodal tutulum' olarak ifade edilir (2). Son yıllarda, lenfomaların sıklığında bir artış görülmekte olup artış özellikle NHL'lerin ekstranodal grubunda belirgindir $(3,4)$. DBBHL çeşitli histolojik, moleküler ve klinik özellikler gösterdiğinden tanıda güçlüklerle karşılaşılabilmektedir. Yayınlanmış bazı çalışmalarda nodal ve ekstranodal tutulumların farklı genetik ve klinik özellikler gösterdiği ortaya konulmuştur $(2,5-8)$. Bununla birlikte ekstranodal tutulumun tedaviye yanıtı ve sağkalım sonuçlarını etkilediği de görülmüştür (9-12). Lenfomalar baş-boyun bölgesinin en sık 3. malignitesi olup ekstranodal tutulumlu DBBHL'lerin 2. sıklıkla tutulum yeri baş-boyun bölgesidir $(13,14)$.

Literatürdeki baş-boyun bölgesi ekstranodal tutulumlu NHL'leri incelendiğinde çalışmaların genellikle heterojen olduğu veya sadece Waldeyer bölgesinin ele alındığı veya gruplara santral sinir sistemi (SSS) bölgesi tutulumlarının dahil edildiği görüldü. Bu nedenle biz çalışmamızda baş-boyun bölgesinde nodal veya ekstranodal tutulum ile başvurarak DBBHL tanısı alan hastaları klinikopatolojik ve toplam sağkalım yönünden inceleyip karşılaştırmayı amaçladık.

\section{HASTALAR ve YÖNTEM}

Bu çalışma Ocak 2015-Ocak 2020 tarihleri arasında Trakya Üniversitesi Tıp Fakültesi Hastanesi Erişkin Hematoloji Kliniği'nde yeni tanı alan DBBHL hastalarında retrospektif olarak Trakya Üniversitesi Tıp Fakültesi Bilimsel Araştırmalar Etik Kurul (2021/331) onayı alınarak yürütülmüştür. Tüm bilgiler elektronik dosyalardan toplanmıştır. Çalışmaya baş boyun bölgesinde nodal veya ekstranodal tutulum ile başvurup DBBHL tanısı alan 52 hasta dahil edildi. Santral sinir sistemi tutulumu olan veya baş boyun bölgesi dışında ekstranodal tutulumu olan veya baş boyun bölgesi dışında bir bölgeden DBBHL tanısı almış olan hastalar çalışmaya alınmadı. Baş-boyun bölgesi ekstranodal tutulumları nazal kavite, paranazal sinüsler, nazofarenks, larenks, tonsil, orofarengeal mukoza, tiroid bezi ve tükrük bezleri olarak tanımlandı. Hastaların yaş, cinsiyet, tanı tarihi, Doğu Kooperatifi Onkoloji Grubu (ECOG) performans skoru, B semptom varlığı, laktat dehidrogenaz (LDH) düzeyi, patoloji raporları (Hans algoritmine göre hücre kökeni, immünhistokimyasal boyama ve Ki 67 proliferasyon indeksi), Ann-Arbor evrelemesi, aldığı tedaviler, tedavi yanıt durumu tarandı (15-18). Uluslararası prognostik indeks (IPI), revize- uluslararası prognostik indeks (R-IPI), Ulusal Kapsamlı Kanser Ağı- uluslararası prognostik indeks (NCCN-IPI) hesaplandı (19-21). Hastaların takip süreçleri ve toplam sağkalım süreleri değerlendirildi. Klinik değerlendirmenin yanısıra tanı anı, ara değerlendirme ve tedavi sonu uygulanmış olan görüntüleme yöntemleri bilgisayarlı tomografi (BT), pozitron emisyon tomografisi (PET), manyetik rezonanas (MR) değerlendirildi. Tedavi yanıtı tam yanıt, kısmi yanıt, yanıtsız veya stabil hastalık olarak Lugano kriterlerine göre değerlendirildi (22).

Devamlı değişkenleri karşılaştırmak için Mann-Whitney-Wilcoxon veya t-test, kategorik değişkenleri karşılaştırmak için $X 2$ veya Fisher's exact testi uygunluğuna göre kullanıldı. Mortalite log-rank testi kullanılarak Kaplan-Meier analizi ile değerlendirildi. İstatistiksel anlamlılık için p değeri $<0.05$ olarak kabul edildi. Tüm istatistiksel analizler için Statistical Package for the Social Sciences (SPSS) programı (versiyon 26, 2019) kullanıldı.

\section{BULGULAR}

Çalışmaya dahil edilen 52 hasta baş-boyun bölgesinin nodal ve ekstranodal tutulumu olarak iki gruba ayrıldı. Ekstranodal grupta 24, nodal grupta ise 28 hasta mevcuttu. Ekstranodal tutulum dağılımları; 10 hastada tonsil, 5 hastada tiroid, 2 hastada nazofarenks, 2 hastada maksiller sinüs, 2 hastada parotis bezi ve diğerlerinde nazal, dil ve bukkal mukoza tutulumu şeklindeydi. Ekstranodal grup- 
ta ortalama yaş 66.5 ve $\% 62.5^{\prime}$ i kadın cinsiyetten oluşuyorken nodal grupta yaş ortalaması 63.1 olup $\% 50$ kadın cinsiyetten oluşuyordu. Gruplar arasında yaş ve cinsiyet dağılımı açısından istatistiksel fark yoktu ( $p$ değerleri sırasıyla $0.427,0.366$ ). Hücre kökeni ekstranodal grupta \%81.8 oranında germinal merkez B hücre benzeri (GMB) iken bu nodal grupta \%46.4 idi. Hücre kökeni iki grup arasında istatistiksel olarak anlamlı farklılık gösteriyordu ( $p$ değeri 0.010). Hastaların Ann-Arbor evrelemesine göre nodal grupta \%78.6'sı ileri evreydi ancak ekstranodal grupta çoğunluğu (\%66.7) erken evre olarak sınıflandırıldı. İki grup evre açısından karşılaştıııldığında p değeri 0.001 ile anlamIı farklılık saptandı. Aynı zamanda ekstranodal grupta \%95 oranında BCL-6 pozitifliği olması nodal gruba göre belirgin olarak yüksek ve istatiksel olarak anlamlı saptandı ( $p$ değeri 0.016). Hastaların demografik, klinikopatolojik özellikleri ve karşılaştırmaları Tablo 1'de gösterilmiştir.

Hastaların kemoterapi protokolleri ve kurs sayısı komorbidite, ECOG performans durumu ve evreleri değerlendirilerek belirlenmiştir. Hastaların \%87.5'inde RCHOP (ritüksimab, siklofosfamid, doksorubisin, prednizon, vinkristin), \%6.25'inde RCVP (ritüksimab, siklofosfamid, prednizon, vinkristin), \%4.15'inde R (ritüksimab)-prednol ve kalanında NORDIC (siklofosfamid, sitarabin, doksorubisin, prednizolon, ritüksimab, vinkristin) protokolü uygulanmıştır. Hastaların tedavi sonu değerlendirmeleri klinik ve görüntüleme yöntemleri ile yapılmış olup nodal grupta hastaların \%67.9'unda, ekstranodal grupta ise \%66.7'sinde tam remisyon sağlandığı görülmüştür ve iki grup sonuçları karşılaştırıldığında istatistiksel bir fark saptanmamıştır ( $p$ değeri 0.927). Toplam 52 hastanın 4'ü (2'si nodal, 2'si ekstranodal) tedaviyi reddetmiş veya tedavi başlanamadan hayatını kaybetmiştir (Tablo 2). Hiçbir hastaya SSS profilaksisi veya radyoterapi uygulanmamıştır. Toplamda nodal grupta 2 hasta birinci basamak tedaviye refrakter olarak değerlendirilmiştir. Bunlardan birinde ikinci basamak tedavi ile remisyon sağlanırken diğerinde tedavi tamamlanamayarak hayatını kaybetmiştir. Ayrıca nodal grupta 1 hasta 6 ay sonra nüks etmiş ve remisyon sağlanarak otolog hematopoetik kök hücre nakli yapılmıştır. Takiplerinde hiçbir hastada SSS nüksü görülmemiştir.

Tablo 1. Çalışma gruplarının demografik özellikleri ve karşılaştırması

\begin{tabular}{|c|c|c|c|}
\hline & Nodal (n: 28) & Ekstranodal (n: 24) & $\mathbf{p}$ \\
\hline Yaş & Ort. \pm SS: $63.1 \pm 13.6$ & Ort. \pm SS: $66.5 \pm 16.5$ & 0.427 \\
\hline Kadın/Erkek (\%) & $50 / 50$ & $62.5 / 37.5$ & 0.366 \\
\hline GMB/GMB dışı (\%) & $46.4 / 53.6$ & $81.8 / 18.2$ & 0.010 \\
\hline $\mathrm{BCL} 2(+)$ & 71.4 & 72.7 & 0.915 \\
\hline $\mathrm{BCL} 6(+)$ & 64.3 & 95 & 0.016 \\
\hline Ki 67 proliferasyon indeksi $(<80 />80)(\%)$ & $78.6 / 21.4$ & $66.7 / 33.3$ & 0.335 \\
\hline Ann Arbor evre (1-2/3-4) (\%) & 21.4/78.6 & $66.7 / 33.3$ & 0.001 \\
\hline B semptomu (+) (\%) & 60.7 & 41.7 & 0.171 \\
\hline $\begin{array}{l}\text { ECOG performans skoru } \\
(0-2 / 3-4)(\%)\end{array}$ & $67.9 / 32.1$ & $58.3 / 41.7$ & 0.477 \\
\hline LDH (yüksek) (\%) & 67.9 & 58.3 & 0.477 \\
\hline $\begin{array}{l}\text { IPI } \\
\text { (düşük-düşük orta/yüksek orta-yüksek) (\%) }\end{array}$ & $50 / 50$ & $58.3 / 41.7$ & 0.548 \\
\hline $\begin{array}{l}\text { RIPI } \\
\text { (iyi-orta-kötü) (\%) }\end{array}$ & $50 / 50$ & $58.3 / 41.7$ & 0.548 \\
\hline $\begin{array}{l}\text { NCCN-IPI } \\
\text { (düşük-düşük orta/yüksek orta-yüksek) (\%) }\end{array}$ & $42.9 / 57.1$ & $50 / 50$ & 0.606 \\
\hline 1. basamak tedavi, remisyon (\%) & 67.9 & 66.7 & 0.927 \\
\hline
\end{tabular}

Ort.: Ortalama, SS: standart sapma, GMB: germinal merkez B benzeri hücre, ECOG: Doğu Kooperatifi Onkoloji Grubu, IPI: Uluslararası prognostik indeks, R-IPI : revize- uluslararası prognostik indeks, NCCN-IPI: Ulusal Kapsamlı Kanser Ağı- uluslararası prognostik indeks.

Tablo 2. Birinci basamak tedavi yanıt değerlendirmesi

\begin{tabular}{lcc} 
& Nodal (n: 28) & Ekstranodal (n: 24) \\
\hline Tam yanıt (\%) & $19(67.9)$ & 0 \\
Progresyon (\%) & $2(7.1)$ & $86.7)$ \\
Tedavi red/eksitus & $7(25)$ & $83.3)$
\end{tabular}




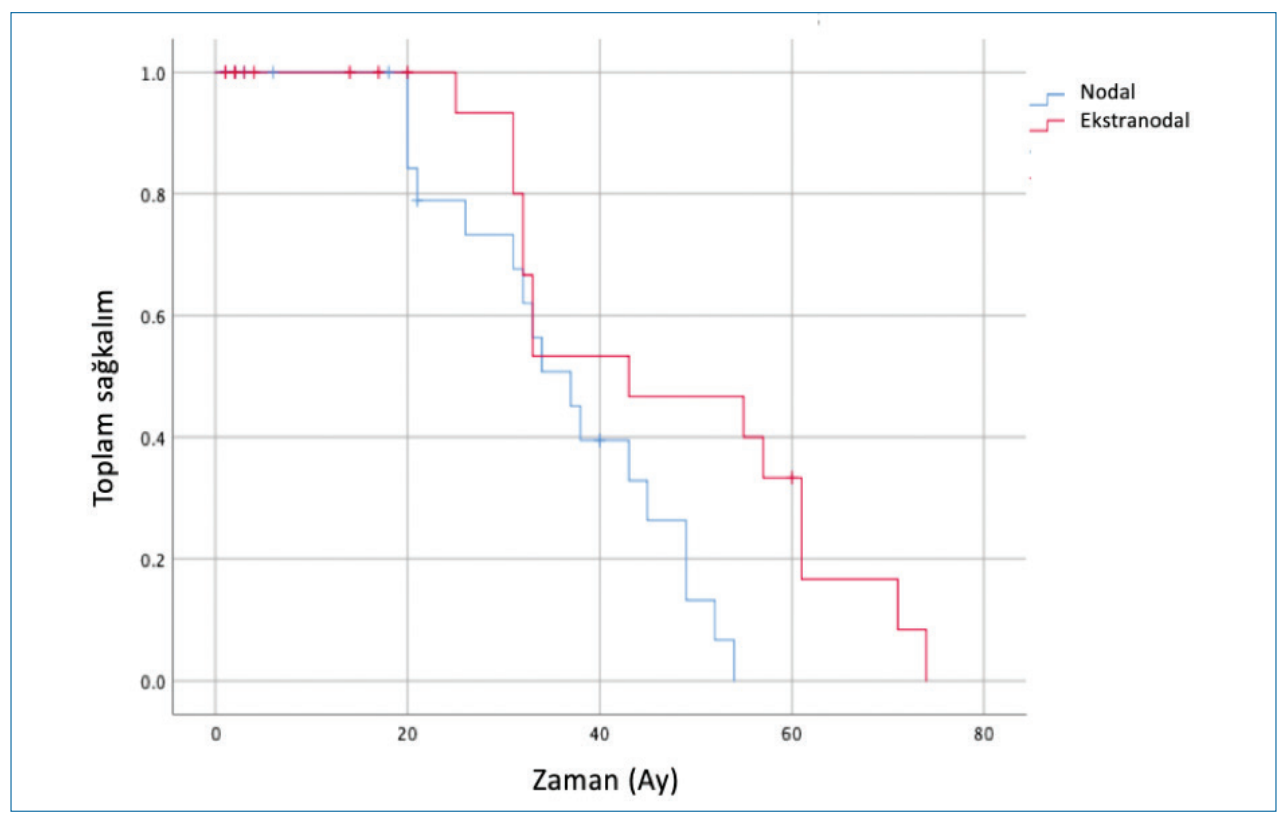

Şekil 1. Kaplan-Meier analizi.

İmmünhistokimyasal yönden değerlendirildiğinde çalışmamızın eksikliği nedeniyle C-MYC nodal grupta 11, ekstranodal grupta 10 hastada bakılamadığından istatistik incelemeye dahil edilememiştir. Floresan in situ hibridizasyon yöntemiyle kesinleştirilerek nodal grupta 2 triple hit, 1 double hit, ekstranodal grupta 1 triple hit vakası tespit edilebilmiştir. Ekstranodal grupta triple hit olarak değerlendirilen hasta 1. basamak tedaviye tam yanıt göstermiş ve remisyonda izlemine devam edilmektedir. Nodal gruptaki double hit olan vaka progresyon göstererek 2. basamak tedavi esnasında kaybedilmiştir. Nodal gruptaki triple hit vakalarından biri tam yanıt sonrası 6 ay sonra nüks etmiş ve kemoterapi ile remisyon sağlanarak otolog hematopoetik kök hücre nakli yapılmıştır. Nodal gruptaki triple hit olan diğer vaka ise 1. basamak tedavisi esnasında kaybedilmiştir.

Hastaların toplam sağkalım (TS) durumu değerlendirildiğinde nodal grupta 17 hasta hayatını kaybederken, ekstranodal grupta 14 hasta hayatını kaybetmiştir (Şekil 1). Ortanca sağkalım süresi nodal grupta 37 ay $(95 \% \mathrm{Cl}$; 30.205-43.795), ekstranodal grupta 43 ay $(95 \% \mathrm{Cl} ; 21.224-$ 64.776) olarak saptandı. Bu süre farklııı̆ı istatistiksel olarak anlamlı bulundu ( $p$ değeri 0.022).

\section{TARTIŞMA ve SONUÇ}

Diffüz büyük $B$ hücreli lenfoma büyük oranda nodal alandan köken almakla birlikte günümüz tedavi yaklaşımlarıyla yüksek oranda kontrolü sağlanabilmektedir. Ancak ekstranodal tutulum, bölge ve sayısına göre prognozu etkilemektedir $(20,21)$. Santral sinir sistemi, kemik/kemik iliği, akciğer, plevra, karaciğer, gastrointestinal sistemden köken alan ekstranodal tutulumların diğer ekstranodal bölgelere göre daha yüksek risk grubunda olduğu ve TS üzerine olumsuz etkileri yapılan çalışmalarla gösterilmiştir $(9,12,21,23,24)$. Bunun yanında baş-boyun, özellikle waldeyer bölgesi gibi bazı ekstranodal tutulumların nodal olanlardan daha iyi seyrettiği gösterilmiştir $(12,25)$. Bu sonucun tutulum bölgesine özgü nedenler, genetik, etiyolojide yer alan immunsupresyon, enfeksiyöz, otoimmuniteden kaynaklandığı çalışmalarla ortaya konulmuş olup çalışmaların bir kısmında ise gruplar arasında klinikopatolojik farklılık görülememiştir (25-28).

Çalışmamızda ekstranodal grup yaş ortalaması 66.5 olup \%62.5 oranında kadın cinsiyetten oluşuyordu ve nodal grup ile istatistiksel olarak anlamlı fark yoktu. Lee ve ark'.ın baş-boyun bölgesi ekstranodal (46 hasta) ve nodal (64 hasta) DBBHL'leri karşılaştırdığı çalışmasında ekstranodal grupta yaş ortalaması daha genç olup 55.6, yaklaşık $\% 70$ oranında erkek cinsiyetten oluşuyordu. Yaş açısından nodal-ekstranodal gruplar arasında çalışmamızda olduğu gibi fark saptanmamıştı (25). Yine benzer hasta grubundan oluşan Sanchez ve arkadaşlarının yaptığı baş-boyun bölgesi DBBHL nodal-ekstranodal tutulumları karşılaştırmasında ekstranodal grup medyan yaşı 70.5 olup gruplar arasında fark yoktu. Ancak ekstranodal gruptaki \%61.8 oranındaki kadın popülasyonu ile gruplar arasında anlamlı cinsiyet farkı saptanmıştır (29). Tüm ekstranodal DBBHL'lerin incelendiği bir çalışmada baş boyun bölgesi analizleri ayrı olarak değerlendirildiğinde bu bölge tutulumunun olduğu grupta yaş ortalaması belirgin yüksek şekilde 82 , kadın cinsiyet ise \%55.6 oranında bulunmuştur (12). Magnoli ve ark'ın yaptığı diğer bir sürveyans incelemesinde de 
baş-boyun bölgesi ekstranodal tutulumu olan grupta 60 yaş üzeri vaka oranı \%69 oranında olup \%52 oranında erkek cinsiyetten oluşuyordu (30).

Çalışmamızda ECOG performansı, IPI, R-IPI, NCCN IPI skorlama, B semptom varlığı, yüksek LDH açısından gruplar arasında fark yoktu. Ancak Ann-Arbor evrelemesine göre ekstranodal vakaların \%66.7'si erken evre iken nodal vakaların \%78.6'sı ileri evreydi. Gruplar karşılaştırıldığında bu fark istatistiksel olarak anlamlı bulundu. Lee ve arkadaşlarının çalışmasında da B semptom varlığı, ECOG performansı açısından gruplar arasında fark gösterilememiştir. Aynı şekilde ekstranodal vakalar Ann-Arbor evrelemesine göre \%71.7 oranında erken evre olmasına rağmen nodal grup ile karşılaştırıldığında istatistiksel fark saptanamamıştır. Fakat LDH nodal grupta anlamlı olarak yüksek bulunmuştur (25). Sanchez ve arkadaşlarının çalışmasında sadece Ann-Arbor evre I ve II olan 34 ekstranodal vakanın \%82.3'i evre I olup nodal grup ile karşılaştırıldığında evre açısından fark yoktu. Bunun yanında gruplar arasında LDH, ECOG performans, B semptom varlığı ve IPI skorları konusunda da anlamlı fark bulunamamıştır (29). Castillo ve arkadaşlarının çalışmasında ekstranodal vakalar \%21 oranında ileri evreydi ve nodal grup ile istatistiksel olarak anlamlı farklılık gösteriyordu (12). Baş-boyun bölgesindeki ekstranodal tutulumları olan hastaların daha erken bası, ağrı gibi semptomlarla başvurarak daha erken evrede tanı almalarının bu farkılığı açıklayabileceği düşünülmektedir.

Çalışmamız hücre kökeni yönünden değerlendirildiğinde germinal merkez benzeri B hücre oranı \%81.8 ile ekstranodal grupta istatistiksel olarak anlamlı yüksek saptandı. Bu sonuç bazı çalışmalarla aynı yönde olup bu durumun ekstranodal grup üzerinde olumlu prognostik etki gösterdiği düşünülmektedir $(25,29,30)$.

İmmünhistokimyasal yönden değerlendirildiğinde çalışmamızın eksikliği nedeniyle C-MYC nodal grupta 11, ekstranodal grupta 10 hastada bakılamadığından istatistik incelemeye dahil edilememiştir. Çalışmamızda BCL-2 ve 6 yönünden BCL 6 anlamlı oranda ekstranodal grupta pozitif saptanmış olup Lee ve arkadaşlarının çalışmasında gruplar arasında fark bulunamamıştır (25). Sanchez ve arkadaşlarının çalışmasında ise çalışmamızdan farklı olarak ekstranodal grupta \%70.6 oranında BCL-6 pozitifliği olmasına rağmen istatistiksel anlamlılık saptanmamış fakat BCL-2 pozitifliği nodal grupta anlamlı olarak yüksek bulunmuştur (29).

Tedavi yanıtı açısından değerlendirildiğinde çalışmamızda 1. basamak tedaviye yanıt gruplar arasında benzer bulunmuştur. Bu sonuç Sanchez ve arkadaşlarının ve Lee ve arkadaşlarının yapmış olduğu çalışmalardaki ekstranodal gruptaki anlamlı yüksek tam yanıt oranlarıyla uyumsuzluk gösteriyordu. Çalışmamızda TS sonuçları ekstranodal grup- ta daha olumlu olmakla birlikte bu diğer çalışmalardaki sonuçlar ile benzerdi $(12,25,29)$. Ancak alt grup analizlerinde paranasal sinüs, nazal kavite tutulumunda TS azalırken, waldeyer tutulumunda daha iyi olduğunu gösteren çalışmalar da mevcuttur (9). Çalışmamızda hasta sayısı yetersiz olduğundan bu açıdan alt grup analizler yapılamamıştır.

Sonuç olarak, çalışmamızda ekstranodal grupta hücre kökeninin büyük oranda GMB özelliğinde olmasının, daha erken semptomatik ve/veya tespit edilebilir klinikte olması ile erken evrede tanı ve tedavi şansının yakalanmasının toplam sağkalım sonuçlarını olumlu yönde etkilediği düşünülmektedir. Ancak nodal grupta hücre kökeninin ekstranodal gruba göre anlamlı olarak agresif özellik göstermesi (GMB dışı) ve hastalığın ileri evrede tanı alabilmesinin prognozu kötü yönde etkilediği sonucuna varılmıştır. Hastaların izlemlerinde progresyon gösteren 2, nüks eden 1 vakanın da nodal grupta olması ve toplam sağkalım sonuçları değerlendirildiğinde nodal hastalığın daha agresif klinikte olduğu görülmüştür. Fakat daha kesin bir yargıya varabilmek için daha fazla hasta sayısıyla yapılmış çalışmalara ihtiyaç vardır.

\section{ETIK KURUL ONAYI}

Çalışma için Trakya Üniversitesi Tıp Fakültesi Bilimsel Araştırmalar Etik Kurulu'ndan onay alındı. (Tarih: 12.07.2021, Karar no: 16/07).

\section{ÇIKAR ÇATIŞMASI}

Yazarların çıkar çatışması bulunmamaktadır.

\section{MALI AÇIKLAMA}

Çalışma için doğrudan veya dolaylı mali destek alınmadı. Çalışma ile ilgili herhangi bir firma veya kişi ile ilgili ticari bağlantı yoktur.

\section{YAZAR KATKISI}

Literatür taranması: OK, TAK, UD; Vakaların takip ve tedavi aşamaları: Tüm yazarlar; Verilerin toplanması: UD, TAK, OK; Makalenin yazımı: OK, TAK, EÜ, AMD; Onaylama: Tüm yazarlar.

\section{KAYNAKLAR}

1. Morton LM, Turner JJ, Cerhan JR, Linet MS, Treseler PA, Clarke CA, et al. Proposed classification of lymphoid neoplasms for epidemiologic research from the Pathology Working Group of the International Lymphoma Epidemiology Consortium (InterLymph). Blood 2007;110(2):695-708.

2. Zucca E, Roggero E, Bertoni F, Cavalli F. Primary extranodal non-Hodgkin's lymphomas. Part 1: Gastrointestinal, cutaneous and genitourinary lymphomas. Ann Oncol 1997;8:727-37.

3. Armitage JO, Gascoyne RD, Lunning MA, Cavalli F. Non-Hodgkin lymphoma. Lancet 2017;390(10091):298-310.

4. Swerdlow SH, Campo E, Harris NL, Jaffe ES, Pileri SA, Stein, H, et al. WHO Classification of Tumors of Haematopoietic and Lymphoid Tissues ( $4^{\text {th }}$ edition). Lyon: IARC Press, 2008. 
5. Raghoebier S, Kramer MH, van Krieken JH, Jong D, Limpens J, Kluin-Nelemans JC, et al. Essential differences in oncogene involvement between primary nodal and extranodal large cell lymphoma. Blood 1991;78(10):2680-5.

6. Kramer MH, Hermans J, Wijburg E, Philippo K, Geelen E, van Krieken JHJM, et al. Clinical relevance of BCL2, BCL6, and MYC rearrangements in diffuse large B-cell lymphoma. Blood 1998;92(9):3152-62.

7. Zucca E, Roggero E, Bertoni F, Conconi A, Cavalli F. Primary extranodal non-Hodgkin's lymphomas. Part 2: head and neck, central nervous system and other less common sites. Ann Oncol 1999;10(9):1023-33.

8. Moller MB, Pedersen NT, Christensen BE. Diffuse large B-cell lymphoma: clinical implications of extranodal versus nodal presentation-a population-based study of 1575 cases. Br J Haematol 2004;124(2):151-9.

9. Takahashi H, Tomita N, Yokoyama M, Tsunoda S, Yano T, Murayama $\mathrm{K}$, et al. Prognostic impact of extranodal involvement in diffuse large B-cell lymphoma in the rituximab era. Cancer. 2012;118(17):4166-72.

10. de Leval L, Bonnet C, Copie-Bergman C, Seidel L, Baia M, Briere $J$, et al. Diffuse large B-cell lymphoma of Waldeyer's ring has distinct clinicopathologic features: a GELA study. Ann Oncol 2012;23(12):3143-51.

11. Validire P, Capovilla M, Asselain B, Kirova Y, Goudefroye R, Plancher $\mathrm{C}$, et al. Primary breast non-Hodgkin's lymphoma: a large single center study of initiaL characteristics, natural history, and prognostic factors. Am J Hematol 2009;84(3):133-9.

12. Castillo JJ, Winer ES, Olszewski AJ. Sites of extranodal involvement are prognostic in patients with diffuse large B-cell lymphoma in the rituximab era: an analysis of the surveillance, epidemiology and end results database. Am J Hematol 2014;89(3):310-4.

13. Cooper JS, Porter K, Mallin K, Hoffman HT, Weber RS, Ang KK, et al. National Cancer Database report on cancer of the head and neck: 10-Year update. Head Neck 2009;31(6):748-58.

14. Vega F, Lin P, Medeiros LJ. Extranodal lymphomas of the head and neck. Ann Diagn Pathol 2005;9(6):340-50.

15. Oken MM, Creech RH, Tormey DC, Horton J, Davis TE, McFadden ET, et al. Toxicity and Response Criteria of the Eastern Cooperative Oncology Group. Am J Clin Oncol 1982;5(6): 649-655.

16. Hans CP, Weisenburger DD, Greiner TC, Gascoyne RD, Delabie J, Ott G, Müller-Hermelink HK, et al. Confirmation of the molecular classification of diffuse large B-cell lymphoma by immunohistochemistry using a tissue microarray. Blood 2004;103(1):275-82.

17. Carbone PP, Kaplan HS, Musshoff K, Smithers DW, Tubiana M. report of the committee on Hodgkin's Diseaase staging classification. Cancer Res 1971;31(11):1860-1.

18. Cheson BD, Horning SJ, Coiffier B, Shipp MA, Fisher RI, Connors $J M$, et al. Report of an international workshop to standardize response criteria for non-Hodgkin's lymphomas NCl Sponsored International Working Group. J Clin Oncol 1999;17(4):1244.
19. The International Non-Hodgkin's Lymphoma Prognostic Factors Project. A predictive model for aggressive non-Hodgkin's lymphoma. N Engl J Med 1993;329(14):987-94.

20. Sehn LH, Berry B, Chhanabhai M, Fitzgerald C, Gill K, Hoskins $\mathrm{P}$, et al. The revised International Prognostic Index (R-IPI) is a better predictor of outcome than the standard IPI for patients with diffuse large B-cell lymphoma treated with R-CHOP. Blood 2007;109(5):1857-61.

21. Zhou Z, Sehn LH, Rademaker AW, Gordon LI, Lacasce AS, Thompson $A C$, et al. An enhanced International Prognostic Index (NCCN-IPI) for patients with diffuse large B-cell lymphoma treated in the rituximab era. Blood 2014;123(6):837-42.

22. Cheson BD, Fisher RI, Barrington SF, Cavalli F, Schwartz LH, Zuc$\mathrm{ca} E$, et al. Recommendations for initial evaluation, staging, and response assessment of Hodgkin and non- Hodgkin lymphoma the Lugano Classification. J Clin Oncol 2014;32(27):3059- 3068.

23. El-Galaly TC, Villa D, Alzahrani M, Hansen JW, Sehn LH, Wilson D, et al. Outcome prediction by extranodal involvement, IPI, R-IPI, and NCCN-IPI in the PET/CT and rituximab era: a Danish-Canadian study of 443 patients with diffuse-large B-cell lymphoma. Am J Hematol 2015;90(11):1041-6.

24. Montalban C, Diaz-Lopez A, Dlouhy I, Rovira J, Lopez-Guillermo A, Alonso S, et al. Validation of the NCCN IPI for diffuse large B-cell lymphoma (DLBCL): the addition of beta2-microglobulin yields a more accurate GELTAMO-IPI. Br J Haematol 2017;176(6):918-28.

25. Lee DY, Kang K, Jung H, Park YM, Cho JG, Baek SK, et al. Extranodal involvement of diffuse large B-cell lymphoma in the head and neck: An indicator of good prognosis. Auris Nasus Larynx 2019;46:114-21.

26. Hart M, Thakral B, Yohe S, Balfour Jr HH, Singh C, Spears M, et al. EBV-positive mucocutaneous ulcer in organ transplant recipients: a localized indolent posttransplant lymphoproliferative disorder. Am J Surg Pathol 2014;38(11):1522-9.

27. Carbone A, Gloghini A, Ferlito A. Pathological features of lymphoid proliferations of the salivary glands: lymphoepithelial sialadenitis versus low-grade B-cell lymphoma of the malt type. Ann Otol Rhinol Laryngol 2000;109(12 Pt 1):1170-5.

28. Kalpadakis C, Pangalis GA, Vassilakopoulos TP, Kyrtsonis MC, Siakantaris MP, Kontopidou FN, et al. Non-gastric extra-nodal marginal zone lymphomas-a single centre experience on $76 \mathrm{pa}$ tients. Leuk Lymphoma 2008;49(12):2308-15.

29. Sánchez LAG, Redondo AM, Blanco Muñez O, Sebastián E, Alcoceba $\mathrm{M}$, González $\mathrm{M}$, et al. Extranodal and nodal diffuse large $B$ cell lymphoma of the head and neck: two different entities? Ann Hematol 2015;94:609-16.

30. Magnoli F, Bernasconi B, Vivian L, Proserpio I, Pinotti G, Campiotti $L$, et al. Primary extranodal diffuse large B-cell lymphomas: Many sites, many entities? Clinico-pathological, immunohistochemical and cytogenetic study of 106 cases. Cancer Genetics 2018;228:28-40. 